\title{
Influence of mist tent therapy on sputum viscosity and water content in cystic fibrosis
}

\author{
M. ROSENBLUTH and V. CHERNICK \\ From the Department of Paediatrics, University of Manitoba, and the Health Sciences Centre, Children's Centre, \\ Winnipeg, Manitoba, Canada
}

\begin{abstract}
Rosenbluth, M., and Chernick, V. (1974). Archives of Disease in Childhood, 49, 606. Influence of mist tent therapy on sputum viscosity and water content in cystic fibrosis. The hypothesis that mist tent therapy decreases the viscosity of sputum by direct liquefaction of the sputum in the lower respiratory tract was tested in 6 patients with cystic fibrosis (CF). The first night all patients slept without the mist tent and the first morning sputum was collected for analysis. The following 2 nights patients were randomly allocated to a tent supplied by either a jet or ultrasonic nebulizer. The early morning sputum was analysed for volume, viscosity, water content, and DNA content, an index of purulence. There was no relation between sputum viscosity and DNA content, water content, or volume. Furthermore, there was no consistent relation between sputum viscosity or volume expectorated and the presence or absence of an 8-hour stay in the tent with either method of water nebulization. These results therefore suggest that mist therapy does not consistently influence sputum viscosity or volume in patients with CF. Above a sputum water content of $90 \%$, further increases in water content do not influence viscosity.
\end{abstract}

The mist tent is a common therapeutic adjunct in patients with CF on the assumption that the excessive pulmonary secretions characteristic of $\mathrm{CF}$ will be thinned, thus facilitating their removal by cilia and cough. It has been assumed that water particles present in the mist tent are deposited in the lower respiratory tract of CF patients. Recent studies by Wolfsdorf, Swift, and Avery (1969) have shown that with normal nasal or mouth breathing the volume of water in aerosol form that is deposited in the lower respiratory tract is only $6 \mathrm{ml}$ and $49 \mathrm{ml}$ per 24 hours for jet and ultrasonic nebulizers, respectively. Bau et al. (1971) have reported that less than $5 \%$ of the aerolized water in the mist tent is deposited in the lower respiratory tract. There are conflicting reports of the influence of mist tent therapy on subsequent pulmonary function (Barker and Levison, 1972; Chang et al., 1973; Doershuk et al., 1968; Matthews, Doershuk, and Spector, 1967; Motoyama, Gibson, and Zigas, 1972; Phelan et al., 1969).

It has been shown that increasing the water content of CF sputum in vitro will lower sputum viscosity in vivo (Lifschitz and Denning, 1970).

Received 17 December 1973.
However, the influence of mist tent therapy on sputum viscosity has not been tested directly in vivo. The present study measures directly the influence of mist tent therapy on sputum water content, viscosity, and volume expectorated in CF patients.

\section{Subjects and methods}

Six patients with productive cough but with stable disease were admitted to the Winnipeg Children's Hospital for a 72-hour period (Table). Their ages ranged from 6 to 16 years, vital capacity from 33 to $88 \%$ of predicted, and Shwachman score from 45 to 65 .

\section{TABLE}

Clinical details of patients studied. The children slept in a mist tent supplied by either an ultrasonic $(U)$ or jet $(J)$ nebulizer on the 2 nd and 3rd days of the study

\begin{tabular}{c|c|c|c|c|c}
\hline $\begin{array}{c}\text { Case } \\
\text { no. }\end{array}$ & $\begin{array}{c}\text { Age } \\
\text { (yr) }\end{array}$ & $\begin{array}{c}\text { Vital } \\
\text { capacity } \\
\text { (\% predicted) }\end{array}$ & $\begin{array}{c}\text { Shwachman } \\
\text { score }\end{array}$ & Day 2 & Day 3 \\
\hline 1 & 16 & 50 & 50 & $\mathrm{U}$ & $\mathrm{J}$ \\
2 & 9 & 55 & 45 & $\mathrm{~J}$ & $\mathrm{U}$ \\
3 & 11 & 35 & 50 & $\mathrm{~J}$ & $\mathrm{U}$ \\
4 & 6 & 33 & 45 & $\mathrm{U}$ & $\mathrm{J}$ \\
5 & 6 & 75 & 65 & $\mathrm{~J}$ & $\mathrm{U}$ \\
6 & 7 & 88 & 65 & $\mathrm{U}$ & $\mathrm{J}$ \\
\hline
\end{tabular}


The initial 24 hours was used as a control period during which the children did not sleep in a tent. During the subsequent 2-day period they slept overnight (for at least 8 hours) in a tent supplied by either a jet nebulizer or a De Vilbiss ultrasonic nebulizer. They were not placed in the tent during the day. The use of a jet or an ultrasonic nebulizer on the second night in hospital was randomly allocated to each child and the type of nebulizer used was reversed on the third night (Table). Distilled water was nebulized and propylene glycol was not used.

The first morning sputum was coughed into plastic vials during postural drainage and the volume was measured. Sputum was collected once before breakfast, later at the same time every morning, and during the afternoon between 13.00 and 14.00 hours. The sputum water content was measured by drying a $1 \mathrm{ml}$ sample to a constant weight in a drying oven.

Sputum viscosity was measured with a Brookfield micro-rheolog viscometer (model $\mathrm{HA}$ ) which can measure viscosity at differing shear rates, being suitable, therefore, for the study of sputum viscosity since sputum viscosity changes with shear rate (non-newtonian). Samples were studied immediately upon collection since preliminary experiments indicated that freezing altered the viscosity readings. A $1 \mathrm{ml}$ sample was placed into the centre of the viscometer plate. The plate was then attached to the viscometer and the sputum allowed to incubate at $37{ }^{\circ} \mathrm{C}$ for 4 minutes without rotation of the cone. Then the sputum was subjected to different rates of shear $(0.5,1 \cdot 0,2 \cdot 5,5,10,20$ r.p.m.) in ascending order for 2-minute intervals. The highest rate of shear achieved was unique for each patient's sputum. At higher shear rates the sputum sample 'creeps' over the edge of the cone causing erratic movements of the recorder pen. Creeping occurred at lower shear rates when viscosity was high. This effect was avoided by ensuring that the maximum r.p.m. used was such that no creeping occurred. The maximum r.p.m. used varied between samples from different patients but was similar for different samples from the same patient. The remainder of the sputum sample was frozen and later analysed for DNA content (Schneider, 1957).

\section{Results}

Sputum volume. The volume of sputum produced by each patient on the morning after the control night and after mist tent therapy nights is shown in Fig. 1. Volume ranged from $3 \cdot 5$ to $18 \cdot 5$ $\mathrm{ml}$. In 3 patients the volume of sputum collected after jet nebulization was less than the control, in 2 patients sputum volume after jet nebulization was greater than the control, and in 1 there was no difference. In 3 patients sputum volume increased after ultrasonic nebulization, in 2 the volume was less than the control, and in Case 4 there was no difference.

Similarly, the influence of mist on the afternoon sputum volume was inconsistent with either type of nebulization. There was an increase in sputum volume in 3 patients and a decrease in volume in the other 3 patients when compared to the control period.

Sputum viscosity. Fig. 2 shows the effect of mist therapy on the viscosity of the morning sputum sample. In 3 patients (Cases 2, 3, and 6) viscosity of sputum at all shear rates after overnight treatment with the ultrasonic and jet nebulizers was greater than viscosity of sputum after the control period. In 2 patients (Cases 4 and 5) viscosity of sputum after overnight treatment with the ultrasonic and jet nebulizers was less than viscosity of sputum of the control. In 1 patient (Case 1) viscosity was greater than the control after ultrasonic nebulization and less than the control after jet nebulization. Viscosity measurements of the afternoon sputum showed a similar inconsistency.

Fig. 3 shows the morning sputum viscosity (measured at 2.5 r.p.m.) in each patient obtained after mist tent therapy with the jet or ultrasonic nebulizer as a percentage of the control value at $2 \cdot 5$

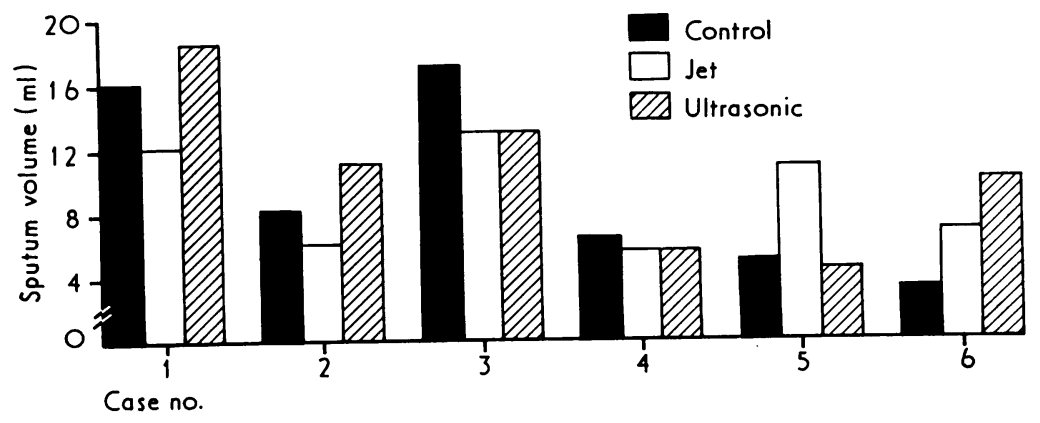

FIG. 1.-Morning sputum volume in 6 CF patients after control period and after an overnight stay in a mist tent supplied with either a jet or ultrasonic nebulizer. 

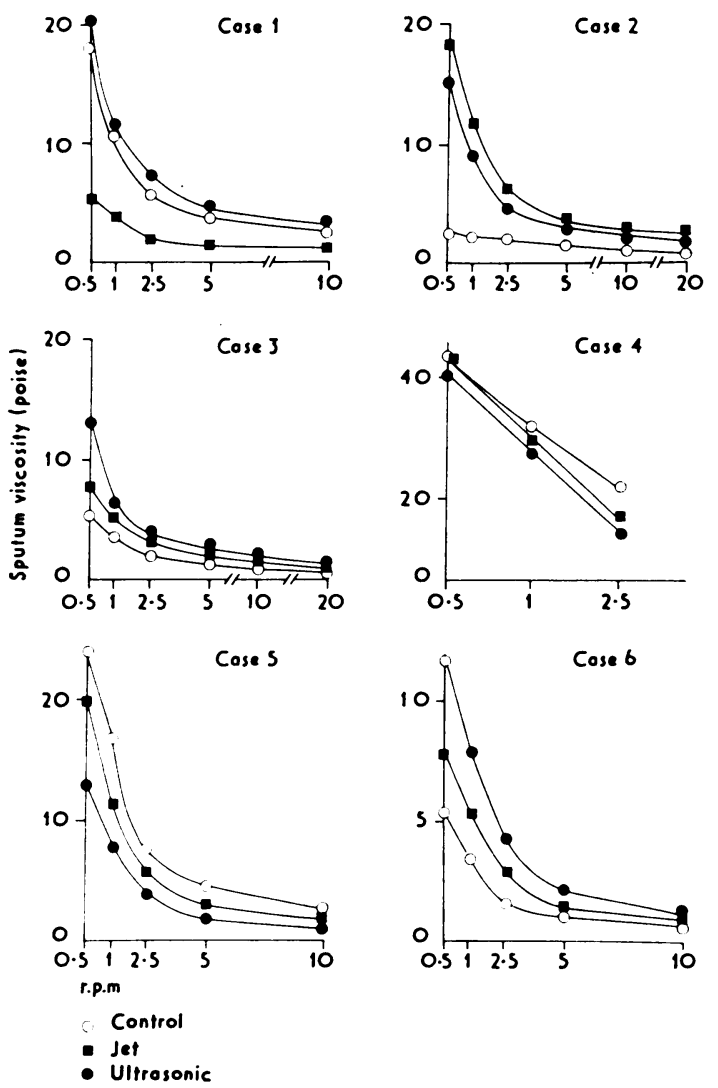

FIG. 2.-Morning sputum viscosity (poise) plotted against shear rate in each of 6 CF patients. Sputum was collected after a control period and after an overnight stay in a mist tent supplied with either a jet or ultrasonic nebulizer.

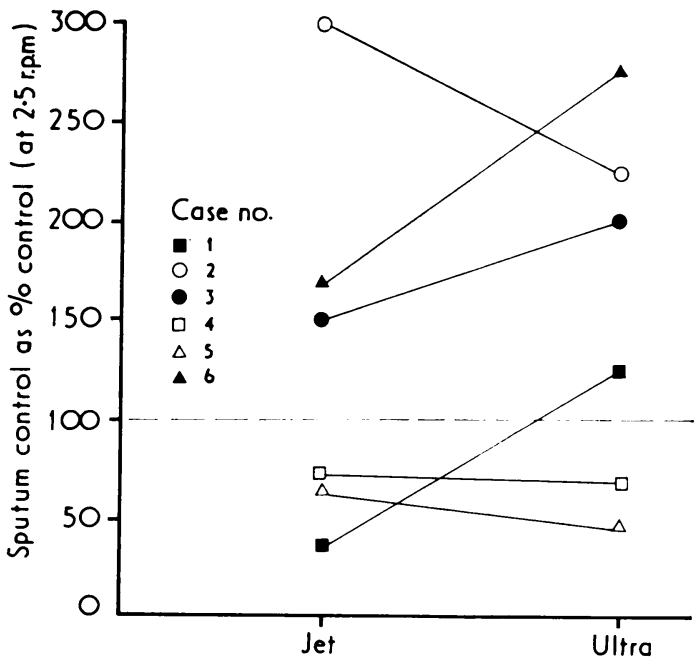

FIG. 3.-Morning sputum viscosity at $2 \cdot 5$ r.p.m. expressed as $\%$ of control value for each patient after jet and ultrasonic mist tent therapy.

r.p.m. On 7 of 12 occasions sputum viscosity was greater than the control value after mist tent therapy. The influence of mist tent therapy on sputum viscosity on the subsequent afternoons was also inconsistent.

Sputum water content. Sputum water content ranged from 86 to $98 \%$ (Fig. 4). On 8 out of 12 occasions after mist tent therapy sputum water content decreased. Similarly, the water content of the afternoon sputum was either unchanged or decreased on 8 out of 12 occasions after mist tent therapy.

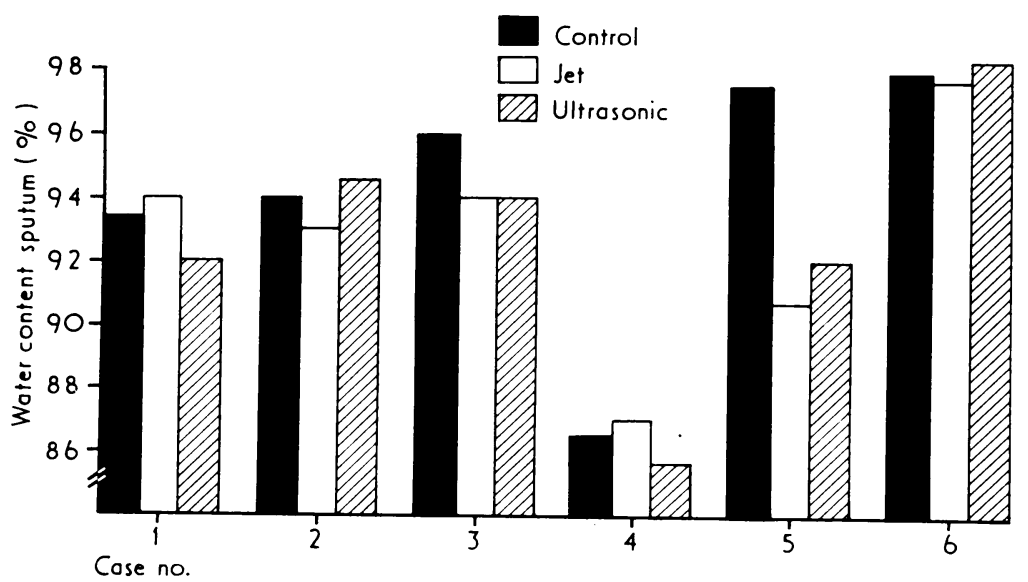

FIG. 4.-Morning sputum water content for each patient after control and mist tent therapy periods. 


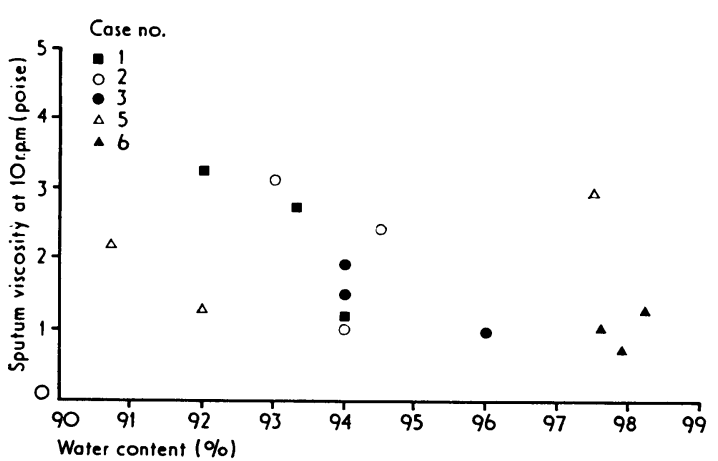

FIG. 5.-Relation between morning sputum viscosity at 10 r.p.m. and sputum water content.

Sputum water content and viscosity. No relation between water content and viscosity was found whether the data were considered as a whole or each patient was considered individually (Fig. 5). Thus, above a water content of $90 \%$ there was no consistent relation between water content and sputum viscosity.

Sputum viscosity and DNA content. Sputum DNA content ranged from $1 \cdot 6$ to $5 \cdot 3$ $\mathrm{mg} / \mathrm{ml}$. There was no relation between viscosity and DNA content whether the data were considered as a whole or each patient was considered separately (Fig. 6).

\section{Discussion}

Nebulization of water is a common adjunct in pulmonary therapy with the rationale that by

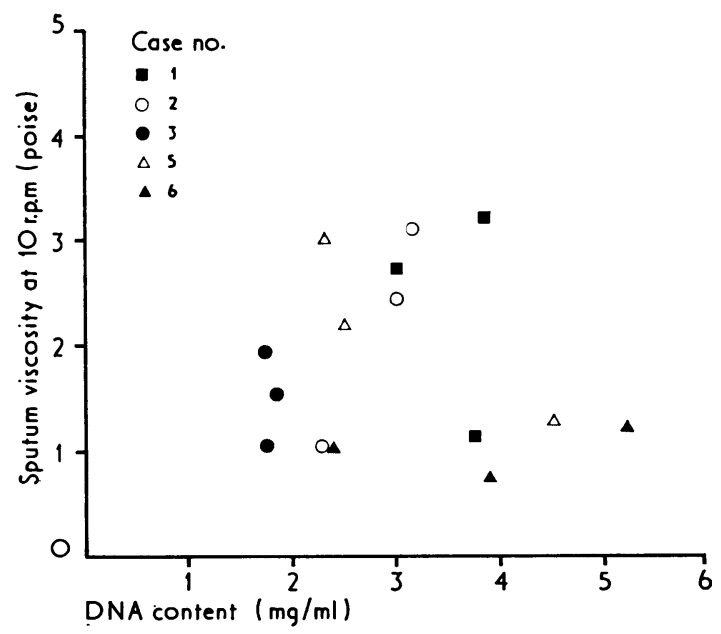

FIG. 6.-Relation between morning sputum viscosity at 10 r.p.m. and sputum DNA content $(\mathrm{mg} / \mathrm{ml})$. increasing the water content of inspired air, liquefaction of exudates and secretions will be affected thereby facilitating their removal by cilia and cough. Thus, it has been assumed that mist tent therapy increases the water content of sputum, thereby lowering its viscosity. Children are encouraged by some clinicians to sleep as much as possible in the tent, and therefore this study was designed to test the effect of an overnight stay in a tent supplied by either a jet or ultrasonic nebulizer. The latter nebulization method has been said to be more effective in promoting drainage of mucus (Matthews et al., 1967).

No attempt was made in this study to compare data between children since the control sputum viscosity was unique for each patient. Thus, sputum obtained from each patient after mist tent therapy was compared to the control value taken after sleeping overnight without a tent. Mist tent therapy with either jet or ultrasonic nebulization failed to produce a consistent change in sputum viscosity. This result confirms and extends the preliminary observations of others (Sturgess and Reid, 1969). In addition, the present experiments failed to indicate an increase in sputum water content with either jet or ultrasonic nebulization. Similarly, there was no significant influence in the volume of the sputum expectorated by either form of aerosol therapy when compared to the control period. We did not show a relation between sputum viscosity and water content above $90 \%$.

Feather and Russell (1970) found that sputum viscosity was related to the degree of purulence of the sputum rather than the underlying disorder. We therefore measured DNA content as an index of sputum purulence, but did not find any correlation with sputum viscosity.

This study does not support the hypothesis that mist tent therapy universally decreases sputum viscosity and enhances the removal of sputum from the lungs of patients with cystic fibrosis.

This study was supported by the Canadian Cystic Fibrosis Research Foundation, Queen Elizabeth II Fund for Research in Diseases of Children, and the Winnipeg Children's Hospital Research Foundation, Inc.

\section{REFERENCES}

Barker, $H$ and Levison, $H$ (1972). Effects of ultrasonically nebulized distilled water on airway dynamics in children with cystic fibrosis and asthma. Fournal of Pediatrics, 80, 396.

Bau, S. K., Aspin, N., Wood, D. E., and Levison, H. (1971). The measurement of fluid deposition in humans following mist tent therapy. Pediatrics, 48, 605.

Chang, N., Levison, H., Cunningham, K., Crozier, D. N., and Grosset, O. (1973). An evaluation of nightly mist tent therapy for patients with cystic fibrosis. American Review of Respiratory Diseases, 107, 672. 
Doershuk, C. F., Matthews, L. W., Gillespie, C. T., Lough, M. D., and Spector, S. (1968). Evaluation of jet-type and ultrasonic nebulizers in mist tent therapy for cystic fibrosis. Pediatrics, 41723.

Feather, E. A., and Russell, G. (1970). Sputum viscosity in cystic fibrosis of the pancreas and other pulmonary diseases. British Fournal of Diseases of the Chest, 64, 192.

Lifschitz, M. I., and Denning, C. R. (1970). Quantitative interaction of water and cystic fibrosis sputum. American Review of Respiratory Diseases, $102,456$.

Matthews, L. W., Doershuk, C. R., and Spector, S. (1967). Mist tent therapy of the obstructive pulmonary lesion of cystic fibrosis. Pediatrics, 39, 176.

Motoyama, E. K., Gibson, L. E., and Zigas, C. J. (1972). Evaluation of mist tent therapy in cystic fibrosis using maximum expiratory flow volume curve. Pediatrics, 50, 299.

Phelan, P. D., Gracey, M., Williams, H. E., and Anderson, C. M (1969). Ventilatory function in infants with cystic fibrosis: physiological assessment of inhalation therapy. Archives of Disease in Childhood, 44, 393.
Schneider, W. C. (1957). Determination of nucleic acids in tissues by pentose analysis. In Methods in Enzymology, Vol. 3, p. 680. Ed. by S. P. Colowick and N. O. Caplan. Academic Press, New York.

Sturgess, G., and Reid, L. (1969). A new pattern of sputum viscosity. In Proceedings of the Fifth International Cystic Fibrosis Conference, p. 368. Ed. by D. Lawson. Cystic Fibrosis Research Trust, London.

Wolfsdorf, J., Swift, D. L., and Avery, M. E. (1969). Mist therapy reconsidered: an evaluation of the respiratory deposition of labelled water aerosols produced by jet and ultrasonic nebulizers. Pediatrics, 43, 799.

Correspondence to Dr. V. Chernick, Health Sciences Centre, Children's Centre, 685 Bannatyne Avenue, Winnipeg, Manitoba, Canada R3E 0W1. 